\title{
Investigating the Fatigue Characteristics of Large Stone Asphalt Mixtures Based on the Disturbed State Concept
}

\author{
Jianhui Wei $\mathbb{D}^{1},{ }^{1}$ Tao Fu, ${ }^{2}$ Yongjun Meng $\mathbb{D}^{2}{ }^{2}$ and Chengming Xiao ${ }^{3}$ \\ ${ }^{1}$ College of Architecture and Civil Engineering, Shangqiu Normal University, Shangqiu 476000, China \\ ${ }^{2}$ College of Civil Engineering and Architecture, Guangxi University, Nanning 530004, China \\ ${ }^{3}$ Road and Bridge Engineering, Guangxi Transport Vocational and Technical College, Nanning 530023, China
}

Correspondence should be addressed to Yongjun Meng; hitmengyj@163.com

Received 18 March 2020; Revised 5 June 2020; Accepted 10 July 2020; Published 19 August 2020

Guest Editor: Meng Guo

Copyright ( $\odot 2020$ Jianhui Wei et al. This is an open access article distributed under the Creative Commons Attribution License, which permits unrestricted use, distribution, and reproduction in any medium, provided the original work is properly cited.

\begin{abstract}
The mechanical response characteristics of large stone asphalt mixtures (LSAMs) are key factors in studying its fatigue characteristics during cyclic loading tests. Based on disturbed state concept (DSC) and viscoelastic continuum damage model (VECD), a series of tests using an overlay test (OT) were carried out to investigate the fatigue characteristics of LSAM. The results showed that disturbance and damage increased with decreasing frequency and increasing loading displacement and aging degree, while the asphalt content had no obvious adverse effect on the increase in damage. In addition, the disturbance and damage grew rapidly in the early stage of loading and reduced in the later stage of loading. On the contrary, based on DSC, the constitutive model modified with disturbance function $(D)$ defined by external work could describe the mechanical properties, and the evolution process of disturbance function $(D)$ could reflect the damage change in cyclic loading tests. The research conclusion can enrich the theoretical research on the fatigue failure response and mechanism of LSAM under cyclic loading and expand the application scope of DSC in the field of pavement.
\end{abstract}

\section{Introduction}

Semirigid materials are prone to fatigue cracking under repeated traffic loads and thermal gradients, which will destroy the pavement structure [1-4]. The inhomogeneity of the internal microstructure of asphalt mixtures will lead to differences in the damage location and mode [5, 6]. External environmental factors, such as test temperatures, aging, and loading, increase the complexity of describing fatigue characteristics of asphalt mixtures $[2,7]$. To improve the fatigue resistance of asphalt mixtures, a variety of innovative products and technologies have been proposed in recent years. It is noteworthy that, with its nominal diameter of the largest dimension greater than $26.5 \mathrm{~mm}$, LSAM has a good retarding effect on crack propagation because coarse aggregates can form a stable skeleton structure [8-11]. A great deal of attention has focus on fatigue behavior of conventional asphalt mixture. However, there are relatively few research studies on LSAM fatigue performance, especially on its constitutive model.
The applications of the viscoelastic continuum damage (VECD) model for predicting the fatigue performance of asphalt mixtures have been widely used in the past two decades [12-14]. Wang and Kim proposed a failure criterion by using the VECD model and considered that the attenuation of the pseudostiffness is a material constant that is independent of the loading mode, temperature, and stress/ strain amplitude [15]. Babadopulos et al. studied the fatigue performance of aged asphalt mixtures using the VECD model [16]. Haddadi et al. used the VECD model to study the fatigue behavior of asphalt mixtures. The material constant $a$ was inversely proportional to the slope of the central part of the relaxation modulus curve obtained by the bending dynamic test with a four-point bending beam device [17]. Sabouri and Kim proposed a new failure criterion using the VECD model and pointed out that the characteristic relationship between the average release rate of the pseudostrain energy and the final fatigue life during fatigue testing of recycled asphalt mixtures and nonrecycled asphalt 
mixtures was independent of the loading mode, strain amplitude, and temperature [18].

Furthermore, numerous studies have proposed quantitative methods for investigating damage and establishment of constitutive models [5, 7, 19-22], but these methods still have some shortcomings in reflecting the damage evolution and establishment of constitutive models of materials. From a macroscopic perspective, the influence of the change in the material structure on the mechanical properties has received increasing attention. The disturbed state concept (DSC) provides a unified modeling method for engineering materials [23-26], which can consider various responses such as elasticity, plasticity, creep, microcracking and fracture, softening, and healing within a unified coupling framework. However, due to the lack of test data for calibration and field measurement for validation, DSC has not been widely used in the field of pavement.

Although the literature shows wide application prospect of VECD in fatigue performance of conventional asphalt mixtures, few studies have applied VECD approach into the results of the OT fatigue test on LSAM. In this study, the OT test is employed to investigate the fatigue performance of LSAM, including assessment the effects on fatigue performance of frequency, loading displacement, asphalt-aggregate ratio, and aging degree. In addition, this paper establishes a constitutive model of LSAM under repeated loading-based DSC model. Disturbance $D$ was used to determine evolution of damage in materials. Meanwhile, the effects of frequency, loading displacement, asphalt-aggregate ratio, and aging degree on fatigue performance and change in disturbance were detected as well. The research conclusion not only enriches the theoretical research on the fatigue performance of LSAM under cyclic loading but also expands the application scope of DSC in the field of pavement.

\section{Materials and Methods}

2.1. Materials and Specimen Preparation. In the test, the binder is AH-70 heavy traffic paving asphalt, the aggregates are limestone aggregates, and the filler is limestone ore powder. The aggregate gradation design for LSAM-30 is shown in Table 1 . The LSAM-30 test results and the technical specifications obtained from the Marshall test are shown in Table 2. Therefore, the optimum asphalt-aggregate ratio is $3.38 \%$. Referring to the method of T0703-2011, which is stipulated in JTG E20-2011 [27], test specimens are trimmed into prismatic specimens with dimensions of $150 \mathrm{~mm} \times 100 \mathrm{~mm} \times 60 \mathrm{~mm}$ originating from a rutting plate with dimensions of $300 \mathrm{~mm} \times 300 \mathrm{~mm} \times 100 \mathrm{~mm}$. In the short-term aging test, the rutting plates were made after the loose asphalt mixture was heated in an oven at $135^{\circ} \mathrm{C} \pm 0.5^{\circ} \mathrm{C}$ for 4 hours $\pm 5 \mathrm{~min}$. Then, the specimens were placed in an oven at $85^{\circ} \mathrm{C} \pm 0.5^{\circ} \mathrm{C}$ for 3 days for the longterm aging test. Unlike the traditional aging test in which the aging time is set to 5 days, the aging time is set to 3 days in this paper. This is because the traditional aging test is equivalent to asphalt pavement, which has been in service for 5-7 years. However, asphalt pavement will crack within 2-3 years.

2.2. Test Methodology. Because the overlay tester (OT) test can directly simulate crack initiation and propagation, to improve the reliability and practicability of OT testing, many research studies have been done on the OT test [28-31]. In the conventional OT test, the triangle waveform cannot reflect the actual pavement stress effectively and the thickness of $38 \mathrm{~mm}$ is not appropriate for the requirements of coarse aggregate. So a haversine loading and thickness of $60 \mathrm{~mm}$ were adopted in subsequent tests. In the previous research results [32], the specimen with a thickness of $60 \mathrm{~mm}$ was simulated by the finite element method. The results show that the LSAM with the thickness of $60 \mathrm{~mm}$ meets the test objectives. The OT test can not only effectively evaluate the reflective cracking of asphalt mixtures but also has good application prospects in studying fatigue cracking and low-temperature cracking.

In the study, test temperature was set at $25^{\circ} \mathrm{C}$, and specific test conditions are shown in Table 3 . The loading displacement waveform is shown in Figure 1. The output data from the OT test are shown in Figure 2. Peak load, number of cycles, and temperature are automatically recorded. An example of measured load and number of cycles is shown in Figure 2(a), and the peak load against number of cycles is shown in Figure 2(b). As shown in Figure 2, with the increase in the number of cycles, the peak load gradually decreases until fracture. During the test, three parallel tests were carried out for each group of specimens, and the average value of the test results was obtained. The specimen gluing process was performed as follows: (1) ensure that the bonding surface of the specimen and base plate was clean; (2) apply Vaseline on the spacer bar and inserted the spacer bar between the base plates; (3) place a piece of tape to cover the gap; (4) glue the specimens to the base plates with epoxy; and (5) add a $2.5 \mathrm{~kg}$ weight on top of the specimen for no less than 24 hours at room temperature. In each group, three specimens were placed in the environment box for no less than 4 hours, and the temperature was set at the test temperature $\pm 0.5^{\circ} \mathrm{C}$. Displacement control was applied during the test.

\section{VECD Model and DSC Model}

3.1. VECD Model. The mathematical expression of the pseudostrain is shown in (1a), where $\varepsilon=D / d$, in which $D$ and $d$ are the tension displacement and steel plate spacing, respectively (shown in Figure 1 ), and $E(t-\tau)$ is relaxation modulus which can be obtained by a Prony series in the first load stage from OT, as shown in (1b):

$$
\begin{gathered}
\varepsilon^{R}(t)=\frac{1}{E^{R}} \int_{0}^{t} E(t-\tau) \frac{\partial \varepsilon}{\partial \tau} \mathrm{d} \tau \\
E(t)=E_{\infty}+\sum_{i=1}^{N} E_{i} e^{-\left(t / \rho_{i}\right)},
\end{gathered}
$$


TABLe 1: Aggregate gradation for LSAM-30.

\begin{tabular}{|c|c|c|c|c|c|c|c|c|c|c|c|c|c|c|}
\hline Diameter $(\mathrm{mm})$ & 37.5 & 31.5 & 26.5 & 19 & 16 & 13.2 & 9.5 & 4.75 & 2.36 & 1.18 & 0.6 & 0.3 & 0.15 & 0.075 \\
\hline Passing rate (\%) & 100 & 97.6 & 86.6 & 70.0 & 63.4 & 57.1 & 49.0 & 34.3 & 24.0 & 16.8 & 11.9 & 8.2 & 5.7 & 4.0 \\
\hline
\end{tabular}

TABLE 2: Marshall test results at an optimal asphalt content.

\begin{tabular}{lccccc}
\hline $\begin{array}{l}\text { Asphalt-aggregate } \\
\text { ratios (\%) }\end{array}$ & $\begin{array}{c}\text { Volume of air voids, } \\
\text { VV (\%) }\end{array}$ & $\begin{array}{c}\text { Voids filled with } \\
\text { asphalt, VFA (\%) }\end{array}$ & $\begin{array}{c}\text { Voids in the mineral } \\
\text { aggregates, VMA (\%) }\end{array}$ & $\begin{array}{c}\text { Marshall stability } \\
(\mathrm{kN})\end{array}$ & $\begin{array}{c}\text { Flow value } \\
(0.1 \mathrm{~mm})\end{array}$ \\
\hline $\begin{array}{l}3.38 \% \\
\begin{array}{l}\text { Specification } \\
\text { requirement }\end{array}\end{array}$ & 3.4 & 59.1 & 11.9 & 30 \\
\hline
\end{tabular}

TABLE 3: The specific test conditions.

\begin{tabular}{|c|c|c|c|c|}
\hline & Frequency $(\mathrm{Hz})$ & Asphalt-aggregate ratios (\%) & Loading displacement amplitude (mm) & Aging \\
\hline Group 1 & $\begin{array}{c}1 \\
5 \\
10 \\
\end{array}$ & 3.38 & 0.3 & Nonaging \\
\hline Group 2 & 5 & 3.38 & $\begin{array}{l}0.1 \\
0.2 \\
0.3 \\
\end{array}$ & Nonaging \\
\hline Group 3 & 10 & $\begin{array}{c}3.38 \\
3.6 \\
3.9 \\
\end{array}$ & 0.3 & Nonaging \\
\hline Group 4 & 10 & 3.38 & 0.3 & $\begin{array}{l}\text { Nonaging } \\
\text { Short aging } \\
\text { Long aging }\end{array}$ \\
\hline
\end{tabular}

where $E(t)$ is the relaxation modulus, $E_{\infty}$ is the long-term equilibrium modulus, $E_{i}$ is the components of relaxation modulus, $\rho_{i}$ is the relaxation time, and $N$ is the number of elements in Prony series.

Based on the concept of the pseudostrain and continuous damage theory, the pseudostiffness $C$ is the ratio of the peak stress to the corresponding pseudostrain [17]:

$$
C=\frac{\sigma}{I \times \varepsilon^{R}},
$$

where $I=\sigma_{1} / \varepsilon_{1}^{R}$ is the variable used to normalize pseudostiffness $C$ and $\sigma_{1}$ and $\varepsilon_{1}^{R}$ are the stress and pseudodisplacement at the end of the first cycle, respectively.

The $C$-S curve under the uniaxial tension test is different from that under the uniaxial compression test. Likewise, the $C$-S curve under the tension-compression test is different from that under the uniaxial tension test. Researchers believe that damage only accumulates in the tensile portion of each cycle [33, 34]. Park et al. [35] calculated the damage parameter $S$ in asphalt mixtures by using the following equation:

$$
\frac{\mathrm{d} S}{\mathrm{~d} t}=\left(-\frac{\partial W^{R}}{\partial S}\right)^{\alpha}
$$

where $W^{R}$ is the pseudostrain energy density function, $\alpha$ is a constant related to the rate of damage growth, and $t$ is the time. $\alpha=1+(1 / m)$ for strain-controlled tests, while $\alpha=1 / m$ for stress-controlled tests, where $m$ represents the maximum slope of the relaxation modulus vs. the time graph in log-log scale. For asphalt mixtures, the functions of the stress and pseudostrain energy density under uniaxial loading are expressed as follows:

$$
\begin{aligned}
\sigma & =\frac{\partial W^{R}}{\partial \varepsilon^{R}}=I C(S) \varepsilon^{R}, \\
W^{R} & =\frac{I}{2} C(S) \varepsilon^{R^{2}} .
\end{aligned}
$$

Damage parameters $S$ are obtained from formulas (3) and (5):

$$
\frac{\mathrm{d} S}{\mathrm{~d} t}=\left[-I \frac{\varepsilon^{R^{2}}}{2} \frac{\mathrm{d} C}{\mathrm{~d} t}\right]^{(\alpha / 1+\alpha)}
$$

In repeated load tests, the following relationships are established:

$$
N=f t \longrightarrow \frac{\mathrm{d} N}{\mathrm{~d} t}=f \longrightarrow \mathrm{d} t=\frac{\mathrm{d} N}{f},
$$

where $N$ is the number of cycles and $t$ is the time. In consideration of $(\mathrm{d} C / \mathrm{d} t)=((\mathrm{d} C / \mathrm{d} N)(\mathrm{d} N / \mathrm{d} t))$ and $(\mathrm{d} S / \mathrm{d} t)=((\mathrm{d} S / \mathrm{d} N)(\mathrm{d} N / \mathrm{d} t))$, the following equation is derived from (6):

$$
\begin{aligned}
\frac{\mathrm{d} S}{\mathrm{~d} N} f & =\left[-I \frac{\varepsilon^{R^{2}}}{2} \frac{\mathrm{d} C}{\mathrm{~d} N} f\right]^{(\alpha / 1+\alpha)}, \\
S_{M} & =\sum_{i=1}^{M}\left[\left(\frac{I}{2}\left(\varepsilon_{i}^{R}\right)^{2}\left(C_{i-1}-C_{i}\right)\right)^{(\alpha / 1+\alpha)}\left(\frac{N_{i}-N_{i-1}}{f}\right)^{(1 / 1+\alpha)}\right],
\end{aligned}
$$



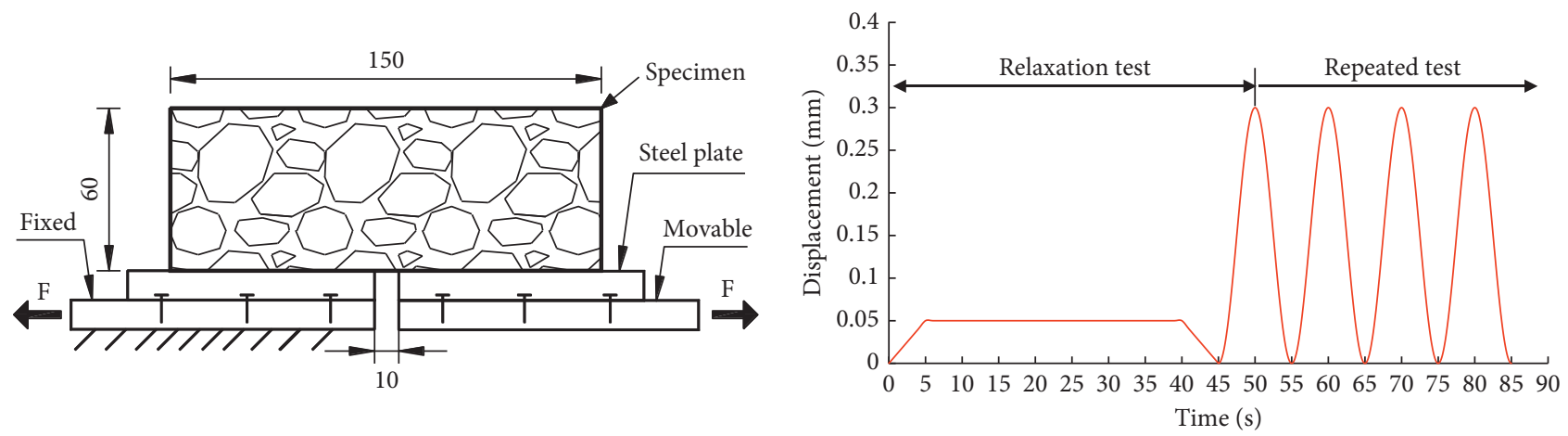

FIgURE 1: Test schematic diagram (unit: $\mathrm{mm}$ ) and test loading model diagram in OT.

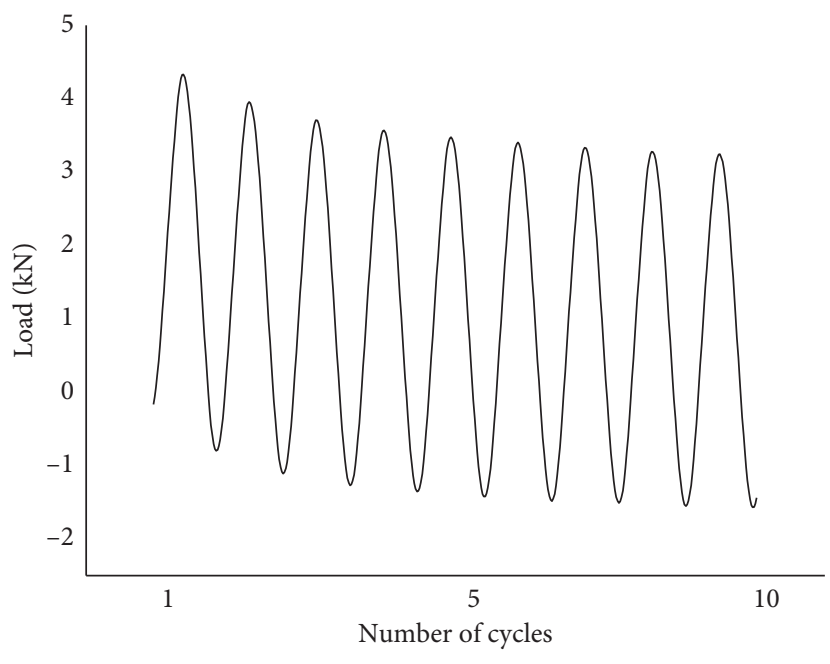

(a)

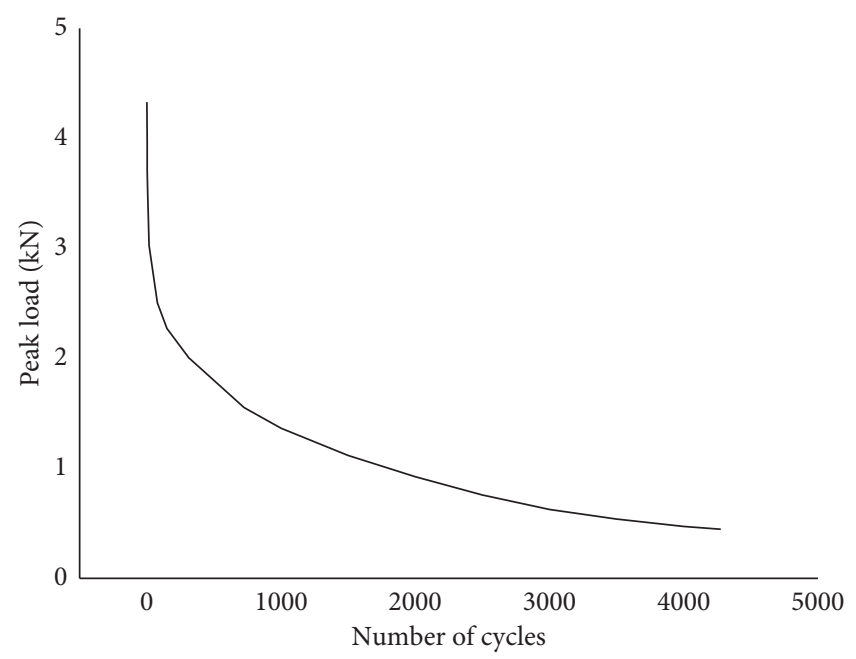

(b)

Figure 2: OT results data: (a) example of load cycles; (b) peak load reduction curve.

where $S_{M}=S\left(N_{M}\right), C_{i}=C\left(N_{i}\right)$, and $\varepsilon_{i}^{R}=\varepsilon^{R}\left(N_{i}\right)$.

3.2. Constitutive Model Based on the DSC. In the DSC model, the forces (mechanical force and thermal and environmental forces) cause a disturbance of the material microstructure, resulting in material changes in the internal microstructure from a relatively intact state (RI) after an automatic adjustment process to a fully adjusted state (FA). This selfadjusting process may involve the relative movement of particles that produce microcracks and damage. It can cause obvious disturbance. This disturbance is defined by a disturbance function $D$, which represents the relationship between the observation response and initial response and describes the evolution of the disturbance with the macroscopic mechanical response to simulate the constitutive relationship of the materials:

$$
\begin{gathered}
d \sigma_{i j}^{a}=(1-D) d \sigma_{i j}^{i}+D d \sigma_{i j}^{c}+d D\left(\sigma_{i j}^{c}-\sigma_{i j}^{i}\right), \\
d \sigma_{i j}^{a}=(1-D) C_{i j k l}^{i} d \varepsilon_{k l}^{i}+D C_{i j k l}^{i} d \varepsilon_{k l}^{i}+d D\left(\sigma_{i j}^{c}-\sigma_{i j}^{i}\right),
\end{gathered}
$$

where $\sigma_{i j}$ and $\varepsilon_{i j}$ are the stress and strain, respectively; $C_{i j k l}$ is the elastic coefficient; and $a, i$, and $c$ represent the observation state, RI, and FA, respectively.

The relative intact (RI) state is defined by an ideal elasticplastic model, and for the uniaxial stress state, the elastic coefficient tensor $C^{e}=E$ ( $E$ is the elasticity modulus). The fully adjusted (FA) state under uniaxial tension is defined based on the approximation of the ultimate asymptotic response of the material, and the ultimate tensile stress $\sigma^{c}$ is defined by the stress during material failure.

Figure 3 shows a schematic diagram of the mechanical response of a material in a DSC model and the first cycle hysteretic loop curve in the low cycle fatigue test. For the loading section of the first period, as shown in Figure 3, the linear relationship between the load and displacement is obvious. It shows that the material maintains an elastic deformation in the first period of loading, and it is considered that there is no damage in the material at this stage. Therefore, the first loading period is considered as the RI; thus, the work of the external force during the first loading process is $W_{0}$. During the loading process, the work done by the external force per cycle is $W_{i}$, and the work done by the external force in the last cyclic loading cycle is $W_{c}$. Thus, the disturbance $D$ is defined as 

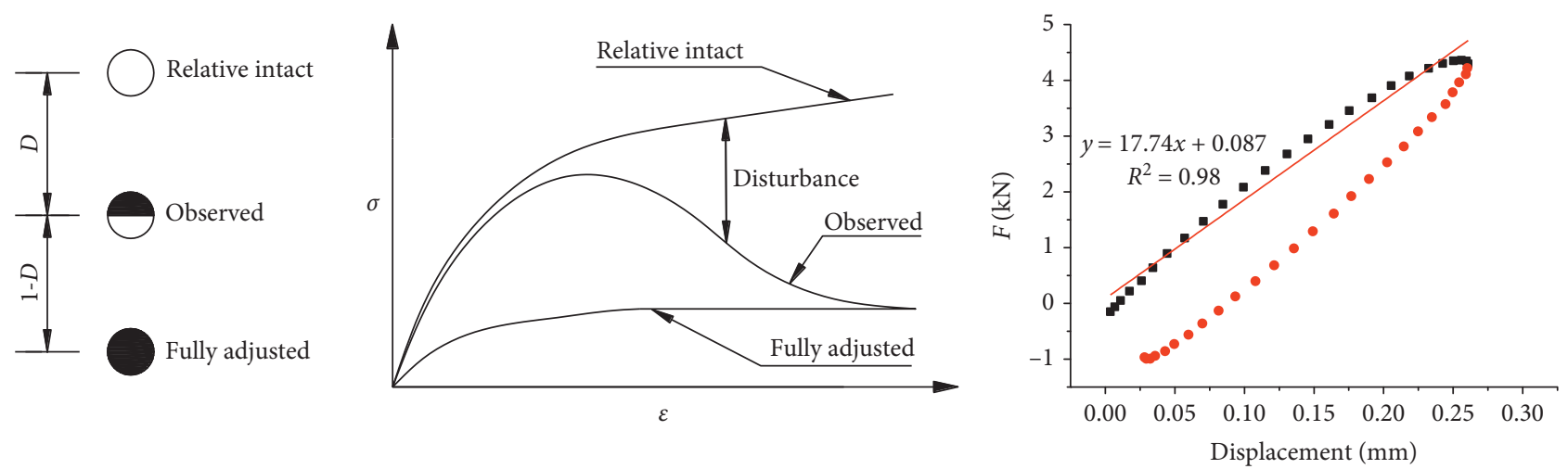

FIGURE 3: Schematic of the stress-strain behavior in the DSC and definition of the initial state.

$$
D=\frac{W_{0}-W_{i}}{W_{0}-W_{c}} .
$$

According to the fatigue test on the asphalt mixture, the cumulative disturbance is nonlinear. The evolution equation of the disturbance can be expressed as follows:

$$
D=1-\left[1-\left(\frac{N}{N_{f}}\right)^{r}\right]^{a},
$$

where $r$ and $a$ are fitting parameters and $N$ and $N_{f}$ are the number of loading cycles and fatigue life, respectively. Based on the RI and FA states and once disturbance is defined, the DSC equations under repeated loading can be derived as

$$
\sigma_{i j}^{a}=(1-D) \sigma_{i j}^{i}+D \sigma_{i j}^{c} \text {. }
$$

After normalizing the peak load of each cycle, (13) can be expressed as follows:

$$
\frac{\sigma_{i j}^{a}}{\sigma_{(1)}^{a}}=(1-D)+D \frac{\sigma_{i j}^{c}}{\sigma_{(1)}^{a}},
$$

where $\sigma_{i j}^{a}$ is the observed stress in the fatigue test, $\sigma_{i j}^{i}$ is the stress in the RA, $\sigma_{i j}^{c}$ is the stress in the FA, $\sigma_{(1)}^{a}$ is the maximum stress in the first loading cycle, and $D=D_{n}$ is the disturbance corresponding to each loading cycle.

\section{Results and Discussion}

In the $C$-S curve (in Figure 4 ), $S$ represents the damage in the specimens during the test, and $C$ represents the normalized pseudostiffness. The slower the $C-S$ curve descends, the longer the curve is, the better the performance of the asphalt mixture will be. It can be seen from Figure 4 that the pseudostiffness decreases with increasing damage, and the rate of decrease in the pseudostiffness in the early stage is faster than that in the later stage. The $C-S$ curves of $5 \mathrm{~Hz}$ and $10 \mathrm{~Hz}$ are higher than that obtained for $1 \mathrm{~Hz}$, which indicates that increasing the frequency can slow down the damage development rate and prolong the service life. The decline rate of the $C$ - $S$ curve of $0.1 \mathrm{~mm}$ is slower than that of $0.2 \mathrm{~mm}$ and $0.3 \mathrm{~mm}$, but the curve of $0.3 \mathrm{~mm}$ decreases faster. This indicated that increasing the loading displacement will accelerate the damage and failure of the specimens. The $C-S$ curve of the asphalt-aggregate ratio of $3.6 \%$ is shorter and lower than that of the other two asphalt-aggregate ratios. The two curves of $3.38 \%$ and $3.9 \%$ indicate that increasing the asphalt content does not substantially improve the tensile strength, but increasing the asphalt content can prolong the fatigue life of the specimens. The $C$ - $S$ curve becomes shorter after aging, and the rate of decrease gradually increases with the aging degree, which indicates that aging has an effect on the fatigue life. The brittleness of the aged asphalt mixtures increases, the damage increases rapidly with increasing aging degree, and the fatigue life of the aged asphalt mixtures decreases.

It can be seen from Figure 5 that the disturbance increases rapidly in the early stage of loading displacement; when the fatigue life ratio is approximately 0.2 , the disturbance increases slowly. This indicates that the integrity of the materials decreases substantially, and the damage increases rapidly during early loading. However, the damage increases slowly, and the rate of cumulative damage slows down during later loading. The disturbance decreases with the increase in the frequency until the fatigue life ratio is approximately 0.8 , which indicates that increasing the loading frequency can prolong the fatigue life. The disturbance increases with the increase in the loading displacement, which indicates that the damage caused by a loading displacement of $0.1 \mathrm{~mm}$ is smaller than that with a larger loading displacement. The disturbance curves of the loading displacements of the $0.2 \mathrm{~mm}$ and $0.3 \mathrm{~mm}$ almost overlap, which indicates that the damage in the specimens under these two conditions does not change substantially. The disturbance curve of the asphalt-aggregate ratio of $3.6 \%$ is higher than that of the other two asphalt-aggregate ratios, which indicates that the damage develops faster when the asphalt-aggregate ratio is $3.6 \%$. Aging will increase the modulus of the asphalt mixture and weaken its tensile strain, so aging will accelerate the development of damage in the specimens. That is, the disturbance increases with the increase in the aging degree.

Figure 6 shows evolution of pseudostiffness with the increasing number of cycles, and it suggests that an exponential function can capture the trend of pseudostiffness with the increasing number of cycles. Equation (15) is an example of fitted exponential function: 


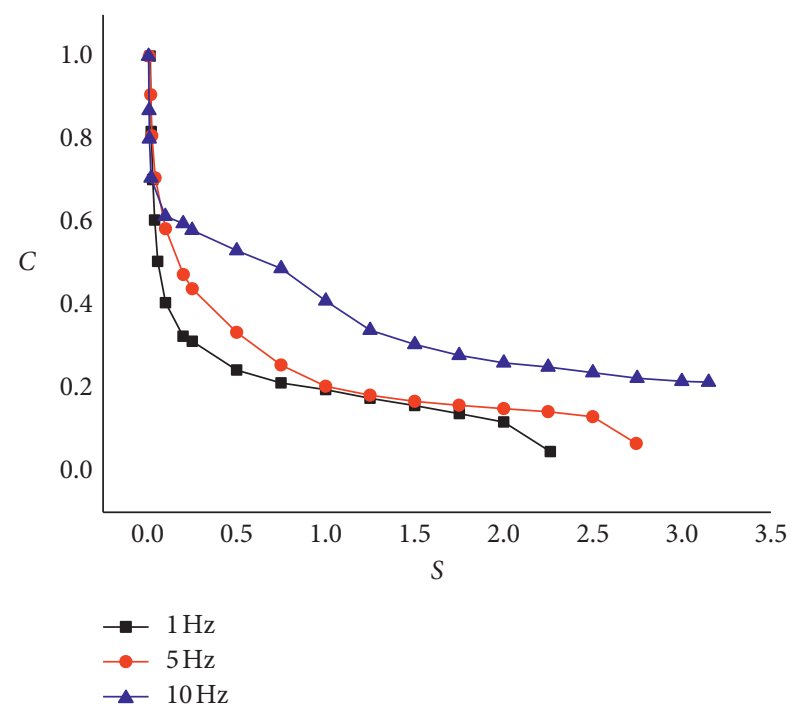

(a)

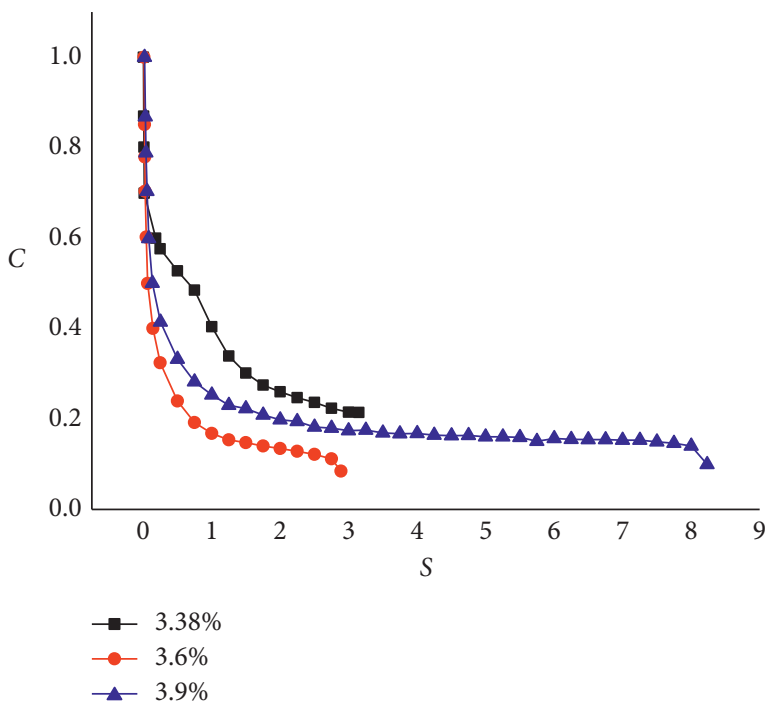

(c)

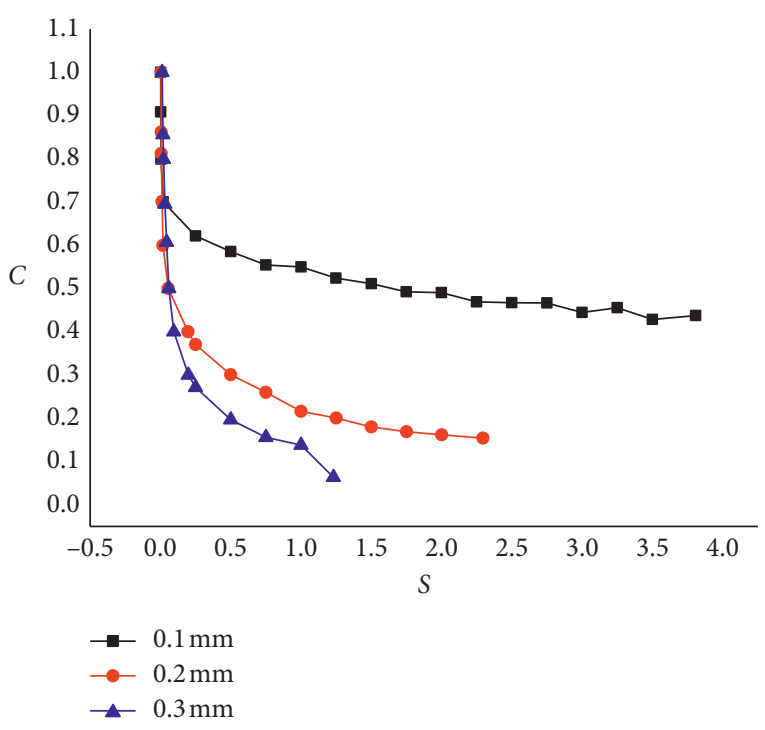

(b)

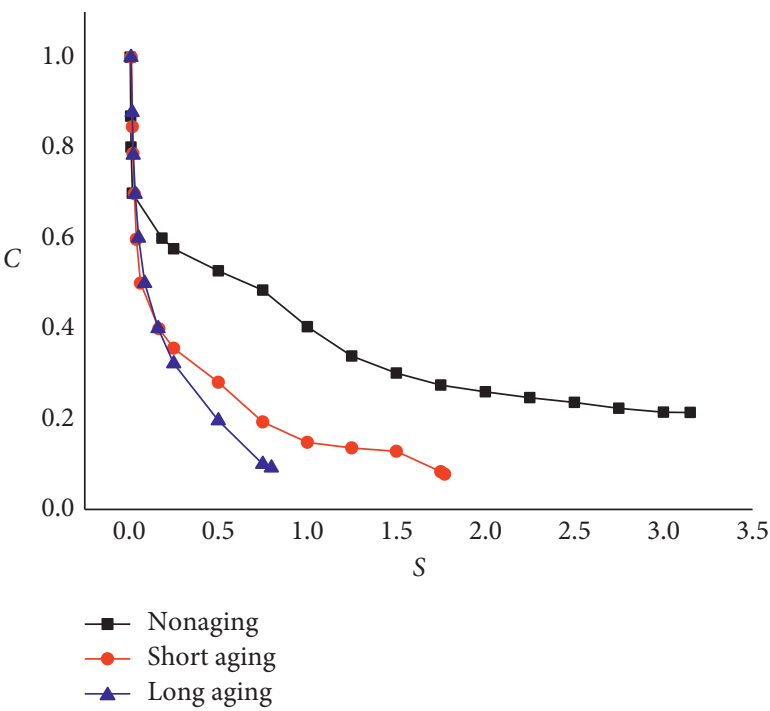

(d)

FIgURE 4: Damage characteristic curves corresponding to (a) frequency, (b) displacement, (c) asphalt-aggregate ratio, and (d) aging degree.

$$
C=1-\exp \left[-A\left(\frac{N}{N_{f}}\right)^{Z}\right]
$$

where $A$ and $Z$ are fitting coefficients. It can be seen from Figure 6 that the curve can be fitted well by an exponential function, and the pseudostiffness develops rapidly in the early stage but slows down in the later stage, which is consistent with the variation trend of the disturbance curve. This indicates that the DSC model proposed in this paper can effectively reflect the evolution of damage.

The calculation results of the parameters in (12) and (15) are shown in Table 4 . It can be seen from Table 4 that parameters $r$ and $a$ increase with increasing frequency. An increasing loading displacement will increase parameter $a$, while parameter $r$ shows a trend of decreasing first and then increasing. The increase in the asphalt content and aging will decrease parameter $a$. Both parameters $A$ and $Z$ decrease with increasing displacement. $Z$ decreases with increasing frequency. Increasing the asphalt content will increase parameter $Z$, while aging will decrease parameter $Z$.

Figure 7 shows the test results and theoretical calculation results of the peak load varying with the loading cycle. The relationship between the peak load obtained from the test and the number of cycles is in good agreement with the calculated results, which indicates that the proposed constitutive model under repeated loading can reflect the variation in its mechanical properties. The increase in the frequency and loading displacement can substantially increase the peak load. The influence of aging and increasing the asphalt content on the peak load is not obvious, but increasing the asphalt content can delay the load attenuation 

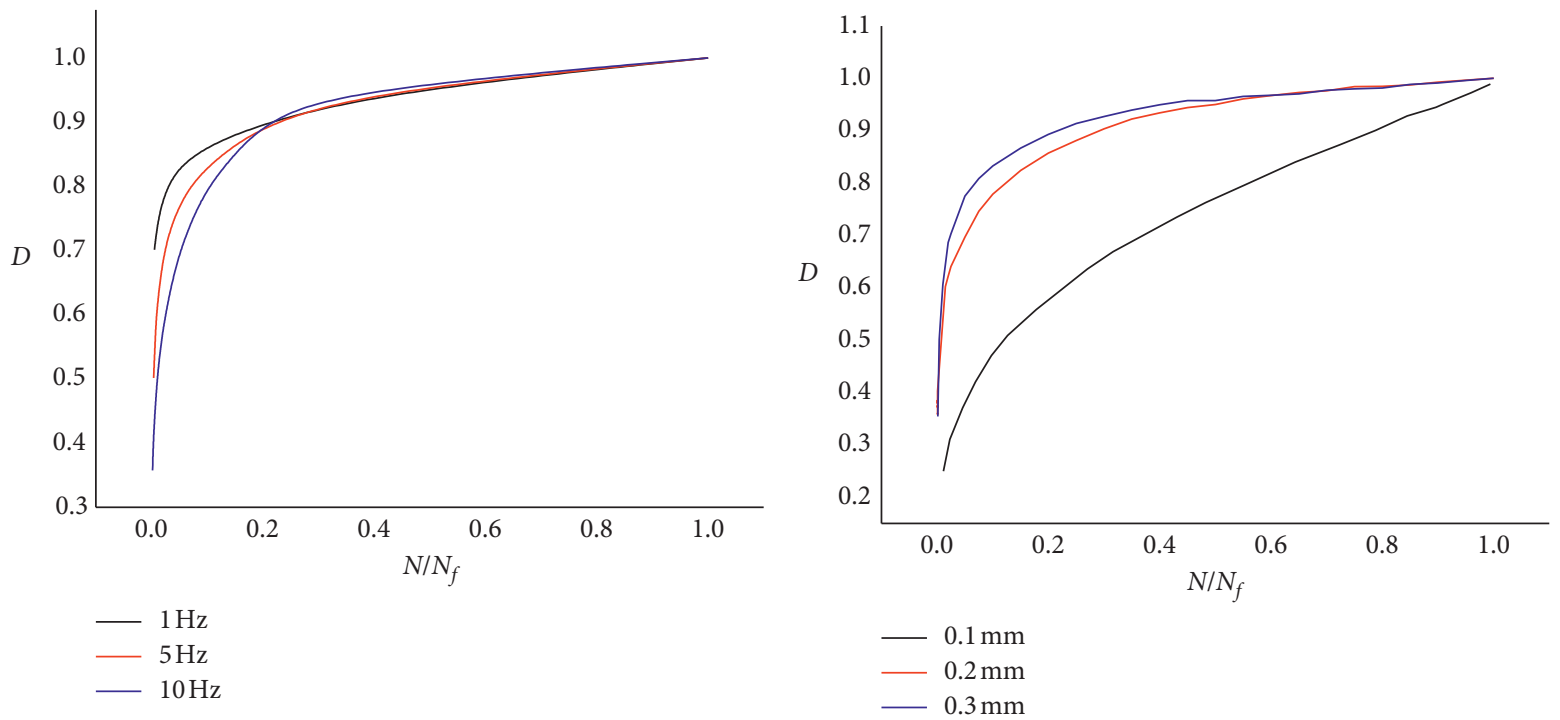

(a)

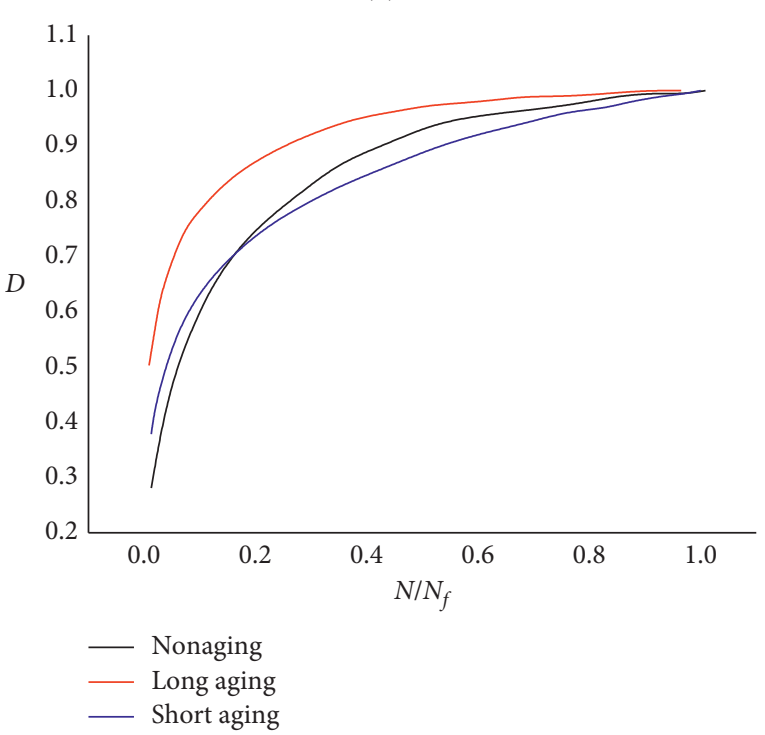

(c)

(d)

FIGURE 5: Disturbance D characteristic curves corresponding to the (a) frequency, (b) loading displacement, (c) asphalt-aggregate ratio, and (d) aging degree.

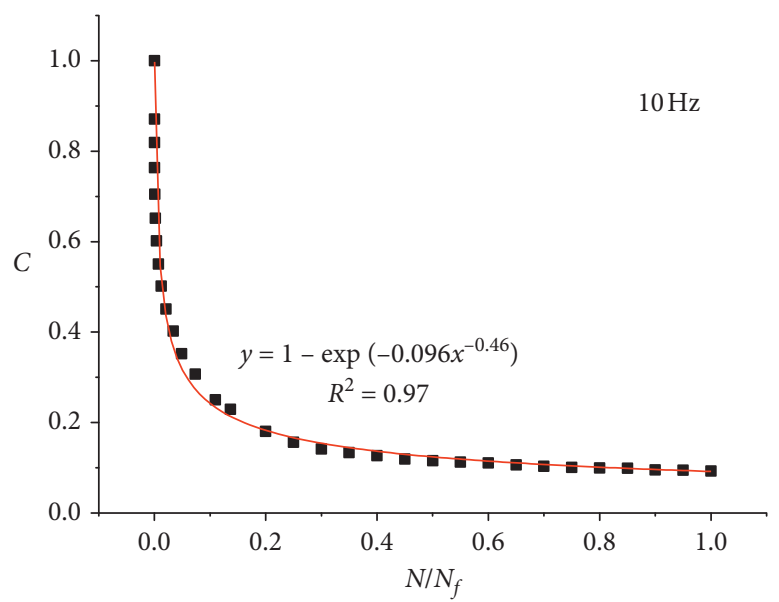

Figure 6: $C-N / N_{f}$ curve $(10 \mathrm{~Hz})$. 
TABLE 4: The calculation parameters.

\begin{tabular}{|c|c|c|c|c|c|}
\hline \multicolumn{2}{|c|}{ Test conditions } & $r$ & $a$ & $A$ & $Z$ \\
\hline \multicolumn{2}{|c|}{ Standard } & 0.4 & 1.93 & 0.159 & -0.422 \\
\hline \multirow{2}{*}{ Group 1} & $1 \mathrm{~Hz}$ & 0.053 & 0.82 & 0.154 & -0.285 \\
\hline & $5 \mathrm{~Hz}$ & 0.25 & 1.8 & 0.125 & -0.379 \\
\hline \multirow{2}{*}{ Group 2} & $0.1 \mathrm{~mm}$ & 0.28 & 0.85 & 0.598 & -0.173 \\
\hline & $0.2 \mathrm{~mm}$ & 0.17 & 1.17 & 0.204 & -0.318 \\
\hline \multirow{2}{*}{ Group 3} & $3.6 \%$ & 0.22 & 1.93 & 0.131 & -0.321 \\
\hline & $3.9 \%$ & 0.25 & 1.34 & 0.194 & -0.253 \\
\hline \multirow{2}{*}{ Group 4} & Short aging & 0.26 & 1.96 & 0.113 & -0.375 \\
\hline & Long aging & 0.24 & 1.18 & 0.151 & -0.435 \\
\hline
\end{tabular}

Note. The standards in Table 4 are as follows: the asphalt-aggregate ratio is $3.38 \%$, the temperature is $25^{\circ} \mathrm{C}$, the loading frequency is $10 \mathrm{~Hz}$, the displacement amplitude is $0.3 \mathrm{~mm}$, and nonaging.

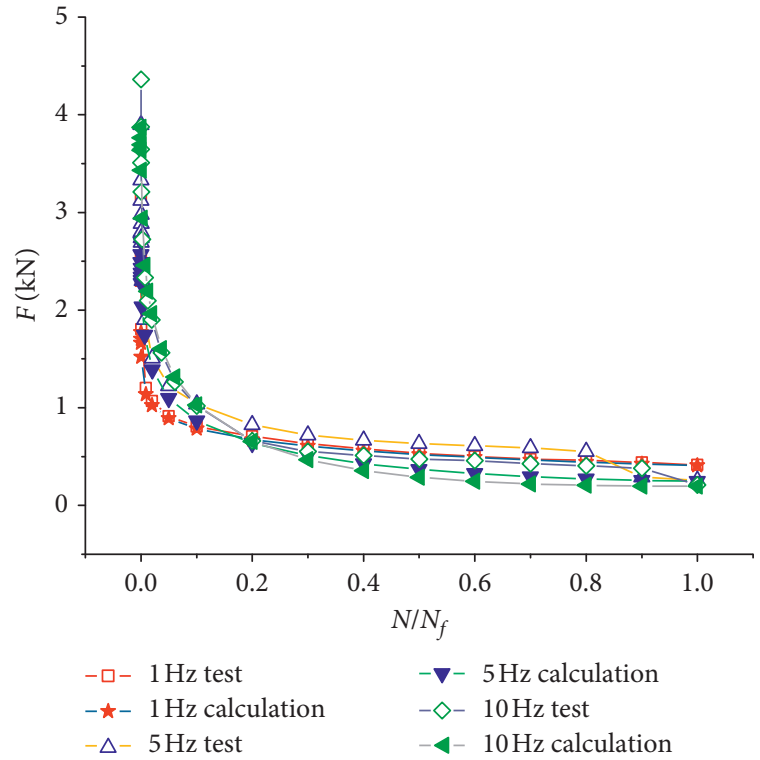

(a)

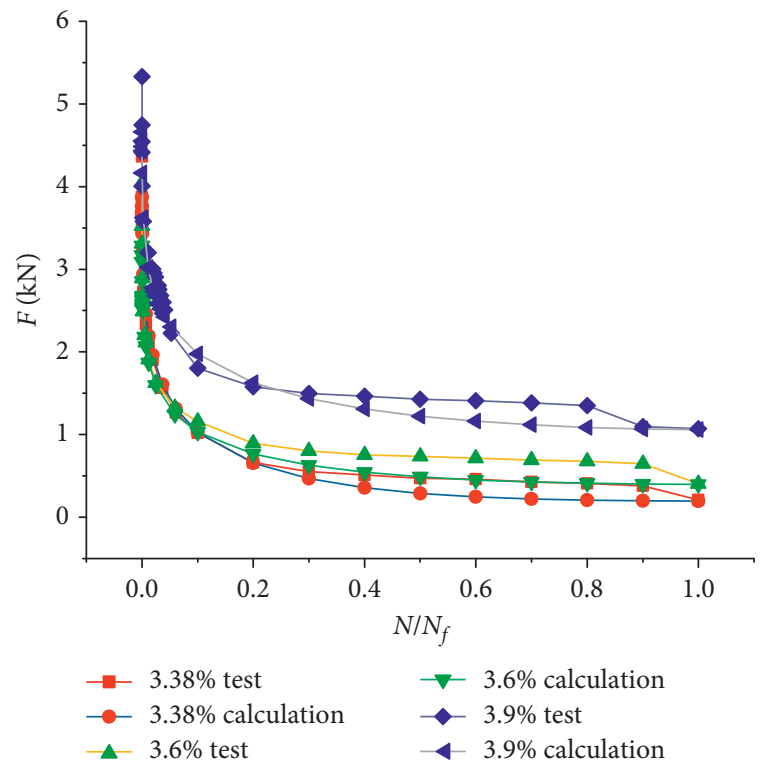

(c)

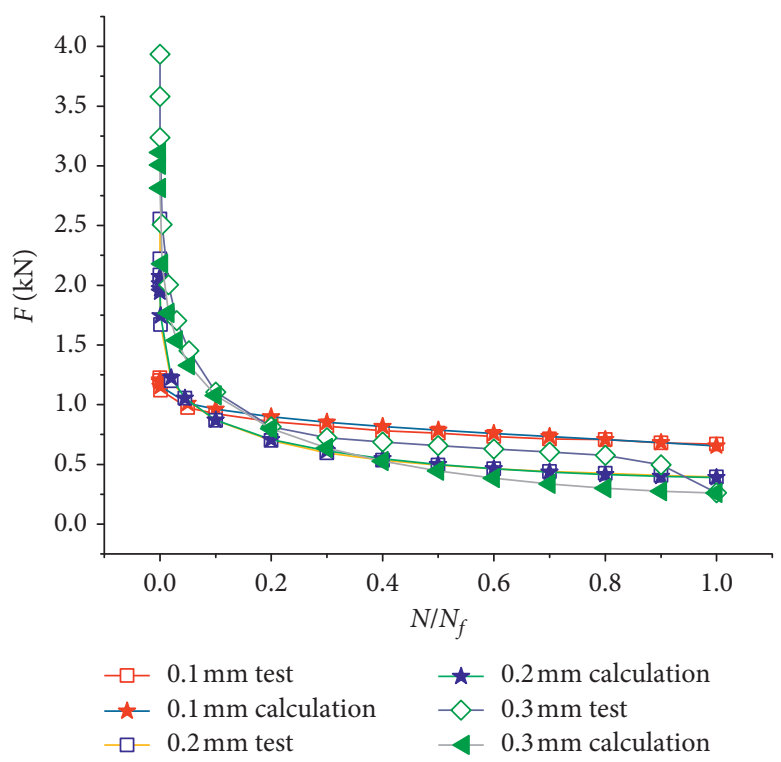

(b)

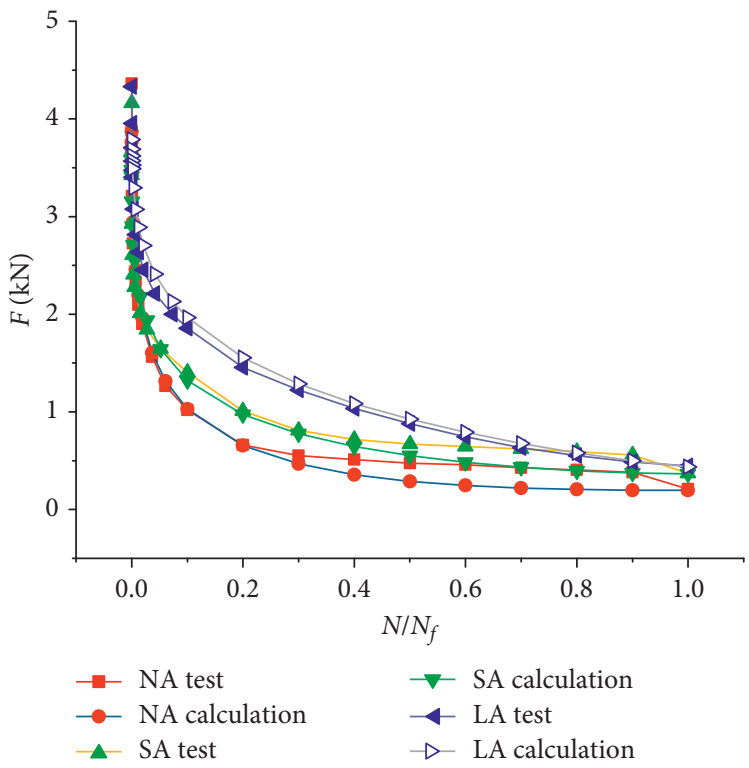

(d)

FIGURE 7: Test and theoretical curves corresponding to the (a) frequency, (b) loading displacement, (c) asphalt-aggregate ratio, and (d) aging degree. 
speed, which is conducive to delaying the development of cracks, while aging can accelerate the load attenuation speed and crack expansion.

\section{Conclusions}

In this paper, a constitutive model of the LSAM under repeated loading is proposed based on the DSC theory. Through the analysis of the fatigue characteristics of the LSAM under different conditions, it is shown that the model proposed in this paper can reflect its mechanical properties, and the disturbance can reflect the damage evolution during the fatigue process. The conclusions are summarized as follows:

(1) Damage develops rapidly in the early stage of loading and slows down in the later stage of loading. Damage increases with the decrease in the frequency, the increase in the loading displacement, and the increase in aging degree. The asphalt content has no obvious adverse effect on the increase in damage.

(2) The magnitude of the disturbance reflects the damage degree. The results show that the disturbance increases with decreasing frequency and increasing loading displacement and aging degree. The pseudostiffness evolution model in this study can reflect the relationship between the pseudostiffness and the number of loading cycles.

(3) The VECD model can effectively reflect the fatigue characteristics of the LSAM. Increasing the loading displacement, decreasing the frequency, and increasing the aging degree will increase the decline rate of the $C-S$ curve. That is, the fatigue life will be shortened.

\section{Data Availability}

The data used to support the findings of this study are available from the corresponding author upon request.

\section{Conflicts of Interest}

The authors declare that there are no conflicts of interest regarding the publication of this paper.

\section{Acknowledgments}

This paper was based on work supported by the National Science Foundation of China (grant no. 51968006).

\section{References}

[1] T. Hu, J. Zi, J. Li, L. Mao, S. Jin, and W. Zhou, "Laboratory and field investigation of interlayer bonding between asphalt concrete layer and semi-rigid base constructed by using continuous construction method," Construction and Building Materials, vol. 150, pp. 418-425, 2017.

[2] J. S. Qian, X. R. Chen, C. Jin, and W. Fu, "Influence of combined load on the performance of geosynthetics as antireflective cracking system in semirigid base asphalt pavements," Journal of Materials in Civil Engineering, vol. 30, no. 9 , p. 7, 2018.

[3] X. Wang, K. Li, Y. Zhong, Q. Xu, and C. Li, "XFEM simulation of reflective crack in asphalt pavement structure under cyclic temperature," Construction and Building Materials, vol. 189, pp. 1035-1044, 2018.

[4] X. Wang and Y. Zhong, "Reflective crack in semi-rigid base asphalt pavement under temperature-traffic coupled dynamics using XFEM," Construction and Building Materials, vol. 214, pp. 280-289, 2019.

[5] E. Masad, V. T. F. Castelo Branco, D. N. Little, and R. Lytton, "A unified method for the analysis of controlled-strain and controlled-stress fatigue testing," International Journal of Pavement Engineering, vol. 9, no. 4, pp. 233-246, 2008.

[6] F. Xiao, P. E. Wenbin Zhao, and S. N. Amirkhanian, "Fatigue behavior of rubberized asphalt concrete mixtures containing warm asphalt additives," Construction and Building Materials, vol. 23, no. 10, pp. 3144-3151, 2009.

[7] S. Lv, C. Liu, J. Zheng, Z. You, and L. You, "Viscoelastic fatigue damage properties of asphalt mixture with different aging degrees," KSCE Journal of Civil Engineering, vol. 22, no. 6, pp. 2073-2081, 2018.

[8] H. B. Guo and S. F. Chen, "Numerical simulation of the reflective crack propagation path for open-graded large stone asphalt mixes," Advanced Materials Research, vol. 152-153, no. 7, pp. 180-183, 2010.

[9] Q. Lu, J. Zi, H. Wang, Q. Huang, and W. Wan, "Coupled numerical analysis of anti-crack mechanism of large stone asphalt mixture," Journal of Highway and Transportation Research and Development (English Edition), vol. 4, no. 2, pp. 22-26, 2010.

[10] X.-l. Wang, X.-m. Huang, and G.-j. Bian, "Mechanism analysis of the use of LSPM for reflection crack prevention of semi-rigid base asphalt mixture," Journal of Highway and Transportation Research and Development (English Edition), vol. 11, no. 3, pp. 8-15, 2017.

[11] Y. Zhao and X. Huang, "Design method and performance for large stone porous asphalt mixtures," Journal of Wuhan University of Technology-Mater. Sci. Ed., vol. 25, no. 5, pp. 871-876, 2010.

[12] W. Cao, A. Norouzi, and Y. R. Kim, "Application of viscoelastic continuum damage approach to predict fatigue performance of Binzhou perpetual pavements," Journal of Traffic and Transportation Engineering (English Edition), vol. 3, no. 2, pp. 104-115, 2016.

[13] A. Norouzi and Y. R. Kim, "Mechanistic evaluation of fatigue cracking in asphalt pavements," International Journal of Pavement Engineering, vol. 18, no. 6, pp. 530-546, 2017.

[14] H. Sadek, E. Masad, H. Al-Khalid, and O. Sirin, "Probabilistic analysis of fatigue life for asphalt mixtures using the viscoelastic continuum damage approach," Construction and Building Materials, vol. 126, pp. 227-244, 2016.

[15] Y. Wang and Y. R. Kim, "Development of a pseudo strain energy-based fatigue failure criterion for asphalt mixtures," International Journal of Pavement Engineering, vol. 20, no. 10, pp. 1-11, 2019.

[16] L. Babadopulos, J. L. S. Ferreira, J. B. Soares, L. A. H. do Nascimento, and V. Branco, "Aging-effect incorporation into the fatigue-damage modeling of asphalt mixtures using the S-VECD model," Journal of Materials in Civil Engineering, vol. 28 , no. 12, p. 11, 2016.

[17] F. Haddadi, M. Ameri, M. H. Mirabimoghadam, and H. R. A. Hosseini, "Validation of a simplified method in viscoelastic continuum damage (VECD) model developed for 
flexural mode of loading," Construction and Building Materials, vol. 95, pp. 892-897, 2015.

[18] M. Sabouri and Y. R. Kim, "Development of a failure criterion for asphalt mixtures under different modes of fatigue loading," Transportation Research Record: Journal of the Transportation Research Board, vol. 2447, no. 1, pp. 117-125, 2014.

[19] X. Luo, R. Luo, and R. L. Lytton, "Characterization of asphalt mixtures using controlled-strain repeated direct tension test," Journal of Materials in Civil Engineering, vol. 25, no. 2, pp. 194-207, 2013.

[20] H. K. Salama and K. Chatti, "Evaluation of fatigue and rut damage prediction methods for asphalt concrete pavements subjected to multiple axle loads," International Journal of Pavement Engineering, vol. 12, no. 1, pp. 25-36, 2011.

[21] Y. Sun, C. Fang, J. Wang, X. Yuan, and D. Fan, "Method of fatigue-life prediction for an asphalt mixture based on the plateau value of permanent deformation ratio," Materials, vol. 11, no. 5, p. 722, 2018.

[22] J. Zhang, Y. D. Wang, and Y. Su, "Fatigue damage evolution model of asphalt mixture considering influence of loading frequency," Construction and Building Materials, vol. 218, pp. 712-720, 2019.

[23] C. S. Desai, "Constitutive modeling of materials and contacts using the disturbed state concept: Part 1-Background and analysis," Computers \& Structures, vol. 146, pp. 214-233, 2015.

[24] C. S. Desai, "Constitutive modeling of materials and contacts using the disturbed state concept: Part 2-Validations at specimen and boundary value problem levels," Computers \& Structures, vol. 146, pp. 234-251, 2015.

[25] C. S. Desai, "Disturbed state concept as unified constitutive modeling approach," Journal of Rock Mechanics and Geotechnical Engineering, vol. 8, no. 3, pp. 277-293, 2016.

[26] S. Zhi, W. W. Gun, L. X. Hui, and T. Bo, "Evaluation of fatigue crack behavior in asphalt concrete pavements with different polymer modifiers," Construction and Building Materials, vol. 27, no. 1, pp. 117-125, 2012.

[27] Research Institute of Highway Ministry of Transport, "Transport RIoHMo: standard test methods of bitumen and bituminous mixtures for highway engineering," China Communications Press, Beijing, China, JTG E20-2011, 2011.

[28] V. Garcia, J. Garibay, I. Abdallah, and S. Nazarian, "Performance of the overlay tester in monotonic and cyclic loading modes," in Proceedings of the International Conference on Transportation and Development, American Society of Civil Engineers, Houston, Texas, June 2016.

[29] V. M. Garcia, J. Garibay, I. Abdallah, and S. Nazarian, "Overlay tester results from dense-graded asphalt concrete mixes: accuracy in characterizing crack susceptibility," Transportation Research Record: Journal of the Transportation Research Board, vol. 2631, no. 1, pp. 30-38, 2017.

[30] J. S. Li, J. Oh, B. Naik, G. S. Simate, and L. F. Walubita, "Laboratory characterization of cracking-resistance potential of asphalt mixes using overlay tester," Construction and Building Materials, vol. 70, pp. 130-140, 2014.

[31] L. F. Walubita, A. M. Faruk, J. Zhang, and X. D. Hu, "Characterizing the cracking and fracture properties of geosynthetic interlayer reinforced HMA samples using the overlay tester (OT)," Construction and Building Materials, vol. 93, pp. 695-702, 2015.

[32] J. H. Wei, J. J. Shi, and J. L. Liang, "Overlay test to investigate the crack propagation of a large-size asphalt mixture," Journal of Materials in Civil Engineering, vol. 32, no. 5, Article ID 04020097, 2020.
[33] J. S. Daniel and Y. R. Kim, "Development of a simplified fatigue test and analysis procedure using a viscoelastic, continuum damage model," in Proceedings of the Association Asphalt Paving Technologists, Colorado Springs, CO, USA, March 2002.

[34] B. S. Underwood, Y. R. Kim, and M. N. Guddati, "Improved calculation method of damage parameter in viscoelastic continuum damage model," International Journal of Pavement Engineering, vol. 11, no. 6, pp. 459-476, 2010.

[35] S. W. Park, Y. Richard Kim, and R. A. Schapery, "A viscoelastic continuum damage model and its application to uniaxial behavior of asphalt concrete," Mechanics of Materials, vol. 24, no. 4, pp. 241-255, 1996. 